\title{
Quarter of a Century after: A Glimpse at the Conformation and Mechanism of Candida antarctica Lipase B
}

\author{
Jarosław Błaszczyk * (D) and Piotr Kiełbasiński \\ Department of Organic Chemistry, Centre of Molecular and Macromolecular Studies, \\ Polish Academy of Sciences, Sienkiewicza 112, 90-363 Łódź, Poland; piokiel@cbmm.lodz.pl \\ * Correspondence: blaszcz8@cbmm.lodz.pl; Tel.: +48-(42)-6803319
}

Received: 13 April 2020; Accepted: 14 May 2020; Published: 16 May 2020

check for updates

\begin{abstract}
Lipase B from Candida antarctica (CAL-B) belongs to the family of $\alpha / \beta$-hydrolases, and is one from the most extensively used biocatalysts in the kinetic resolution of amines and alcohols in a racemic state, in the desymmetrization of diacetates or diols, and in the stereoselective synthesis of chiral intermediate compounds for obtaining the various pharmaceuticals and agents which protect plants. There are also many cases of promiscuous reactions catalyzed by CAL-B. The number of very important results appeared recently in the literature in the years 2015-2019, regarding the crystal structure and conformation of CAL-B molecule. Before 2015, there was a long period of a complete lack of information concerning this enzyme's structure. The earlier reports about CAL-B structure were dated between 1994-1995, and did not provide enough conclusions about the mechanism of the enzyme. The recently solved structures give a hint of the enzyme mechanism in three dimensions.
\end{abstract}

Keywords: CAL-B; crystallographic polymorphism; enzyme promiscuity; lipase activity; esterase activity; macromolecular crystallography; lipase B; Candida antarctica

Among commercially available lipases, which are nowadays expressed in large quantities, lipase $B$ from Candida antarctica (CAL-B) is one of the most commonly used biocatalysts, both in research and in industry [1-3]. CAL-B is an $\alpha / \beta$-hydrolase which follows the same mechanism of action as the other serine hydrolases $[4,5]$. This enzyme is highly stereoselective in a wide variety of chemical transformations [6]. A wide variety of CAL-B usage includes the kinetic resolution of racemic amines or alcohols, or the desymmetrization of diacetates and diols [7-10]. There are many reports about the stereoselective synthesis of asymmetric reaction intermediates for the production of a wide variety of pharmaceuticals and plant-protecting agents [11-13]. Moreover, there are many cases of promiscuous reactions catalyzed by CAL-B, including aldol reactions, Michael additions, cyclic esters, or the polymerization of vinyls [14-20]. In order to improve activity, thermostability, stereoselectivity, or expression rate of CAL-B, and to adapt it for different applications, a structural mutagenesis has been widely developed, with the focus on kinetic resolution of asymmetric alcohols [2]. For improvement of expression of CAL-B enzyme in Escherichia coli and improvement of the enzyme stability, an anion tag has been added, and the conformationally mobile residues which belong to the active center were mutated. The crystal structures of CAL-B, with such sequence modifications, were determined: PDB entries $4 \mathrm{~K} 6 \mathrm{G}, 4 \mathrm{~K} 6 \mathrm{H}, 4 \mathrm{~K} 6 \mathrm{~K}, 4 \mathrm{~K} 5 \mathrm{Q}$ [21] and 3W9B [22]. Since the truncated loop variant, cp283 $\Delta 7$, showed an important increase in the enzyme catalytic activity, the two crystal structures of that variant, in an apo form and with a bound inhibitor (PDB structures 3ICV and 3ICW, respectively), were determined [23].

The studies on applying commercially available CAL-B enzyme to the synthesis of asymmetric non-racemic heteroorganic molecules, are carried out in our lab for many years [24-26]. We modeled 
the reactions, promoted by the wild-type CAL-B enzyme, of hydrolysis of acetoxymethyl (i-propoxy)-phenylphosphine oxide and its analog, which contains a $P$-borane moiety. These theoretical calculations showed how the substrate could possibly be accommodated in the active center [25].

Among the CAL-B crystal structures known to 2016, there were only eight structures reported for the wild-type of this enzyme: four of an unligated form: PDB entries 1TCA, 1TCB, 1TCC [27], and 4ZV7 [28], and four of the complexed forms: PDB entries 1LBS, 1LBT [29], and 5A6V, 5A71 [30]. Among these eight entries, five were reported in 1994-1995: 1TCA, 1TCB, 1TCC, 1LBS, and 1LBT, while last three entries were reported 21 years later, in 2015-2016: 4ZV7, 5A6V, 5A71. Therefore, there is a huge time gap, before the three newer structures appeared in the literature. The reasons could include unexpected problems in purification, since some proteins tend to be unstable in solution, or problems in obtaining the perfect chemical and conformational purity of the protein for the purpose of crystallization [31-34].

Structurally, CAL-B is a macromolecule with about $33 \mathrm{kDa}$ size and the number of 317 amino acid residues in its wild-type polypeptide chain [28]. CAL-B belongs to the $\alpha / \beta$ protein family. The order of $\alpha$-helices and $\beta$-strands is illustrated in Figure 1 [27]. The seven $\beta$-strands create a $\beta$-sheet which is located in the core of the molecule. The last six of them are parallel. There are ten $\alpha$-helices: the first helix is located right before the $\beta 1$ strand. Four helices interact with $\beta$-strand: $\alpha 3, \alpha 4$, and $\alpha 7$ from one side of the $\beta$-sheet, and $\alpha 2$ from the other side. The helices $\alpha 5, \alpha 6$, and $\alpha 10$ contribute most to the active center, and play crucial role in substrate specificity and enzyme activation. The overall conformation of the molecule is stabilized by the presence of three disulfide bridges: Cys22-Cys64, Cys216-Cys258, and Cys293-Cys311 [35]. The presence and connectivity of these disulfide bridges, correspond well in all structures listed above. In general, the active site is created by a "catalytic triad": Ser105-His224-Asp187, and an "oxyanion hole" (residues Thr40 and Gln106). The oxyanion hole most likely influences the transition state of the reaction [5]. The His224 residue is the first residue in the $\alpha$-helix 9, and this side chain is directed into the active center. The aspartic acid 187 belongs to a turn after $\beta$-strand 6 . The oxygen atoms of Asp187 side chain are hydrogen-bonded to the main chain and to a conserved water molecule [27].

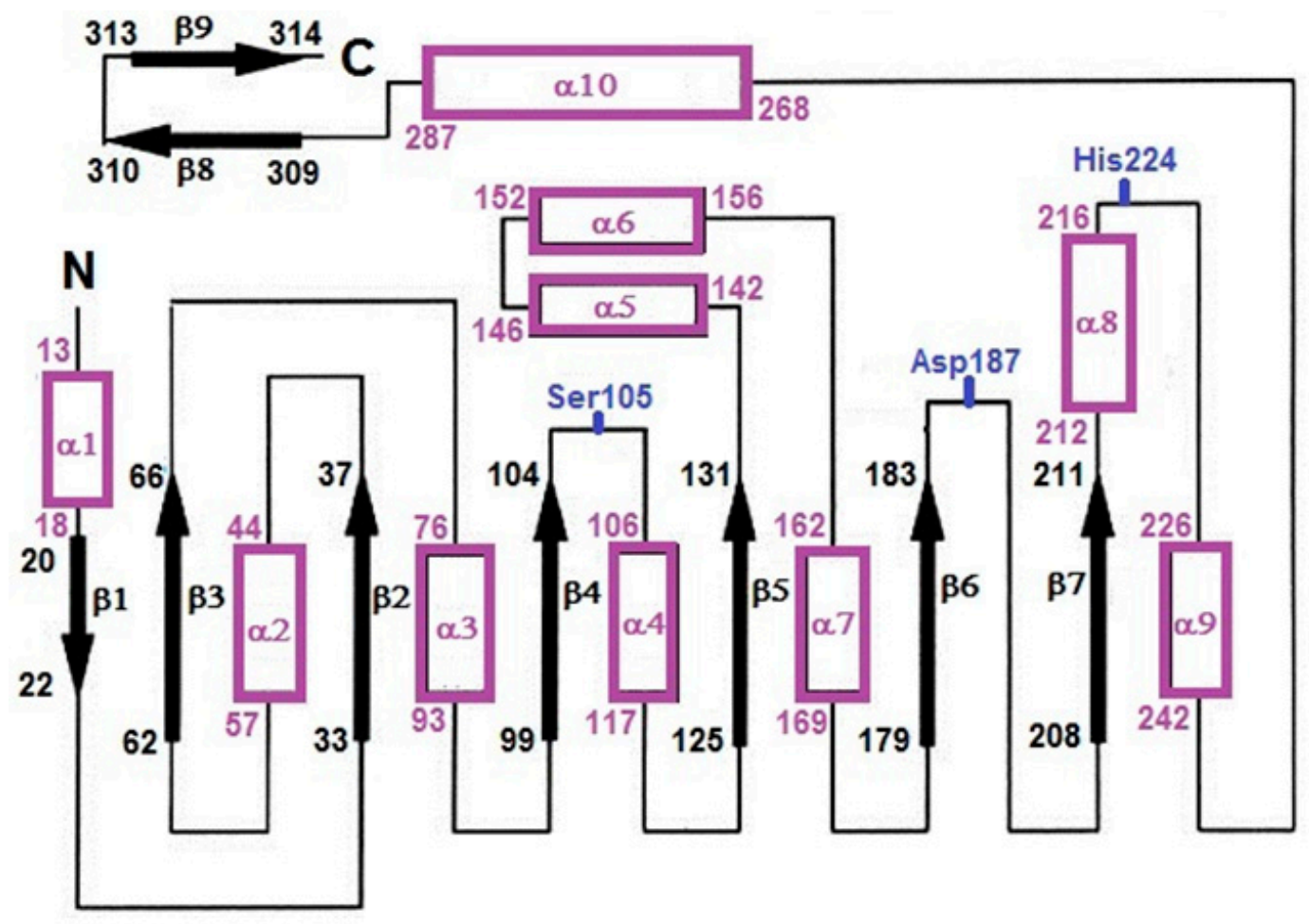

Figure 1. Secondary structure diagram of the Candida antarctica (CAL-B) molecule [27]. 
Five structures, which were solved in the mid-1990's, were the only known CAL-B structures, and could not tell us much about the enzyme mechanism and whether this mechanism is assisted with conformational change of the macromolecule. While the structures 1TCA, 1TCB, 1TCC were apo forms, the two structures 1LBS and 1LBT were complexed with ligands, 1HEE and T80, respectively (see Figures 2 and 3; 1HEE: n-hexylphosphonate ethyl ester; T80: methylphenta (oxyethyl)heptadecanoate, Tween-80). Both these ligands were bound nonspecifically with the protein, i.e., nonbound to any side chain from the catalytic Ser-His-Asp triad (see Figures 2 and 3) [29].

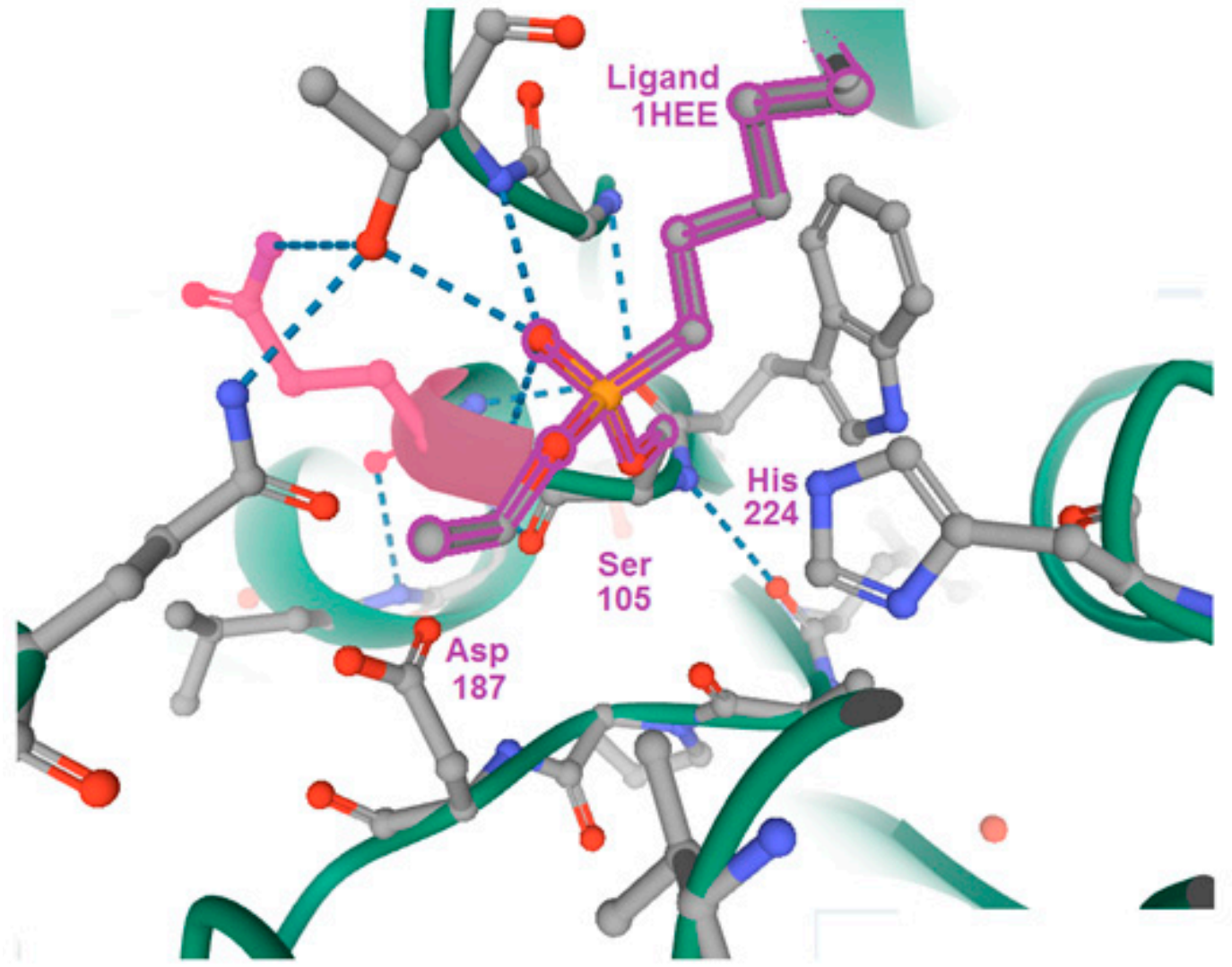

Figure 2. Nonspecifically bound ligand $1 \mathrm{HEE}$, present in the active site of CAL-B in PDB structure 1LBS [29]. The Figure was created using RCSB PDB Jmol software [36,37].

Very notable progress has been made after the quarter of the century. The three structures: 4ZV7, $5 \mathrm{~A} 6 \mathrm{~V}$, and 5A71, were reported in mid-2010's, and revealed opened and closed conformational states of the glycosylation site which could shed light on conformational behavior of the enzyme. The two triclinic structures 5A6V and 5A71 were complexed CAL-B forms [30], and a hexagonal structure 4ZV7 was an apo form [28].

The fold of hexagonal form 4ZV7 was almost identical as in orthorhombic 1TCA form. In both structures, the NAG (N-acetyl-D-glucosamine) molecules are present in the glycosylation site, and are bound to the side chain $\mathrm{N} \delta 2$ atom of Asn74 residue. Interestingly, the NAG chains in both structures differ a lot in their conformation. In hexagonal form, the side chain of Asn74 and two bound visible NAGs rotate straight away from the protein molecule towards the solvent region. In orthorhombic form, this side chain and the two bound NAGs rotate towards the macromolecule, closing the glycosylation site. The torsion angle N-C $\alpha-C \beta-C \gamma$ of Asn74, which shows rotation at the $\mathrm{C} \alpha-\mathrm{C} \beta$ bond, is different by about 70 degrees. Following this observation, the authors raised the question of whether the opening (in hexagonal form) and closing (in orthorhombic form) of the glycosylation site could be just an effect of the crystal packing, or whether it could be related to the opening and closing the active center during catalytic cycle of the enzyme [28]. Of special interest was the location of one water 
molecule, bound to the O 82 atom of the residue Asp187 and to O $\gamma$ atom of Ser227. This water, in orthorhombic 1TCA structure is located in same place and has the same connectivity. The connectivity of this water in monoclinic form 1TCB is almost identical to 1TCA. Since the active center in hexagonal form contains more water molecules, the active sites display some differences in conformation of catalytically important side chains [28].

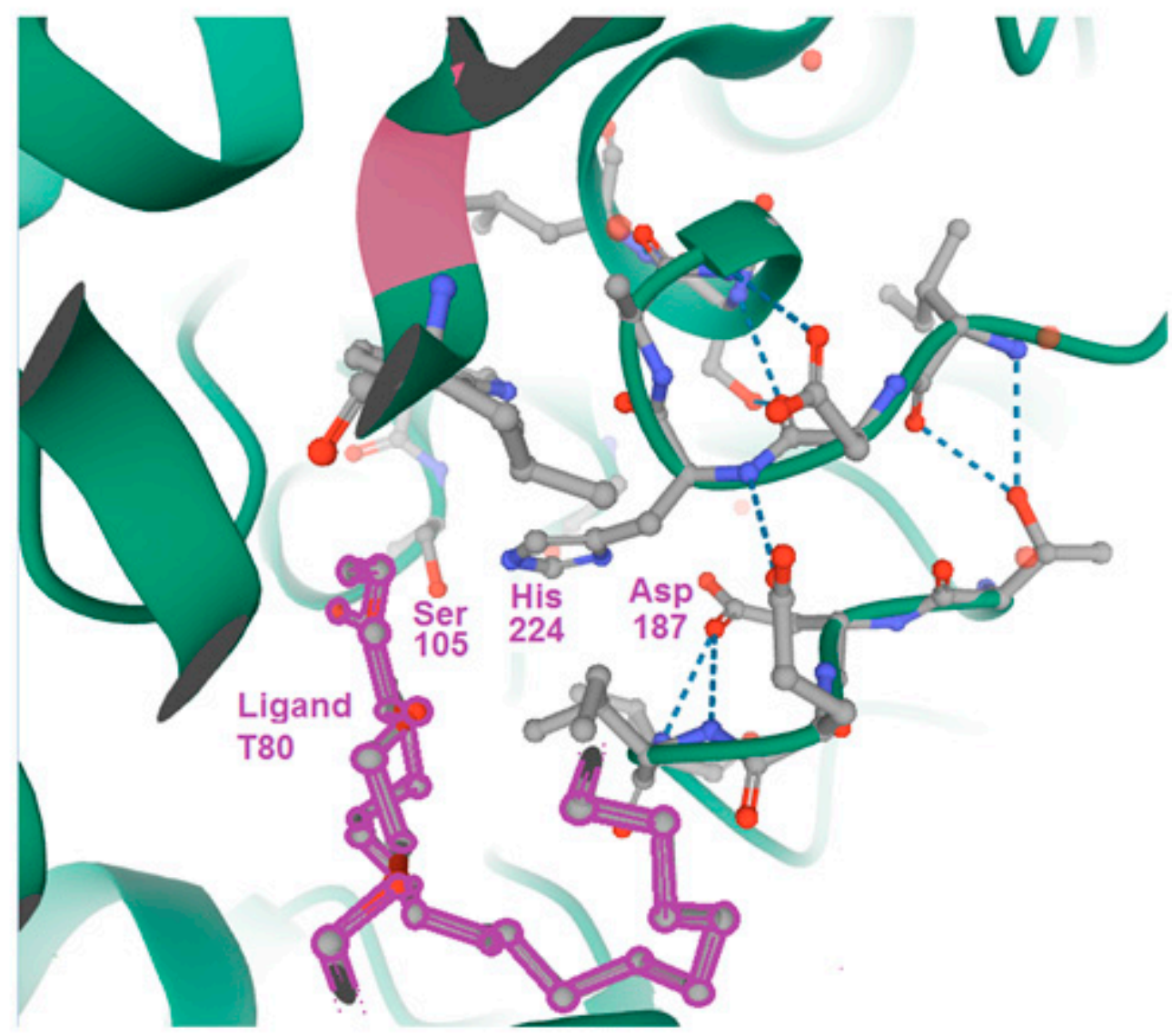

Figure 3. Nonspecifically bound ligand T80, present in the active center of CAL-B in PDB structure 1LBT [29]. The Figure was created using RCSB PDB Jmol software [36,37].

The ligand-free, wild type CAL-B crystal structure, represented by the PDB structure 1TCA, is the most referenced structure in CAL-B studies, and shows an intermediate conformational state between the lipase and esterase activity [38]. The existence of CAL-B conformations, which correspond to lipase (open) and esterase (closed) activity, gives perspective for the structure-based CAL-B design [38].

In 2015, the crystal structure of CAL-B, which contains both opened and closed conformations in the same asymmetric unit, was solved [30]. Refined at atomic $(0.91 \AA)$ resolution, the PDB structure $5 \mathrm{~A} 71$ is the structure determined at the highest resolution so far among all triacylglycerol lipase (EC 3.1.1.3) crystal structures [30]. These findings made it possible to elucidate the mechanism of CAL-B, with particular implications for the catalytic behavior and lipase classification. The asymmetric unit of PDB entry 5A71 contained two independent protein monomers A and B. In monomer A, an $\alpha$-helix 5 which involves residues 140 to 147, follows the "classical" opened conformation in 1TCA structure (Figure 4). The residue range Leu140-Leu147 in monomer B undergoes dramatic conformational change, to form an unfolded loop (see Figure 4) [30]. Residues 140-147 in molecule A, which create an $\alpha$-helix, correspond to open conformation, while these residues in molecule B which unfold to a loop shape, correspond to closed conformation [30]. 

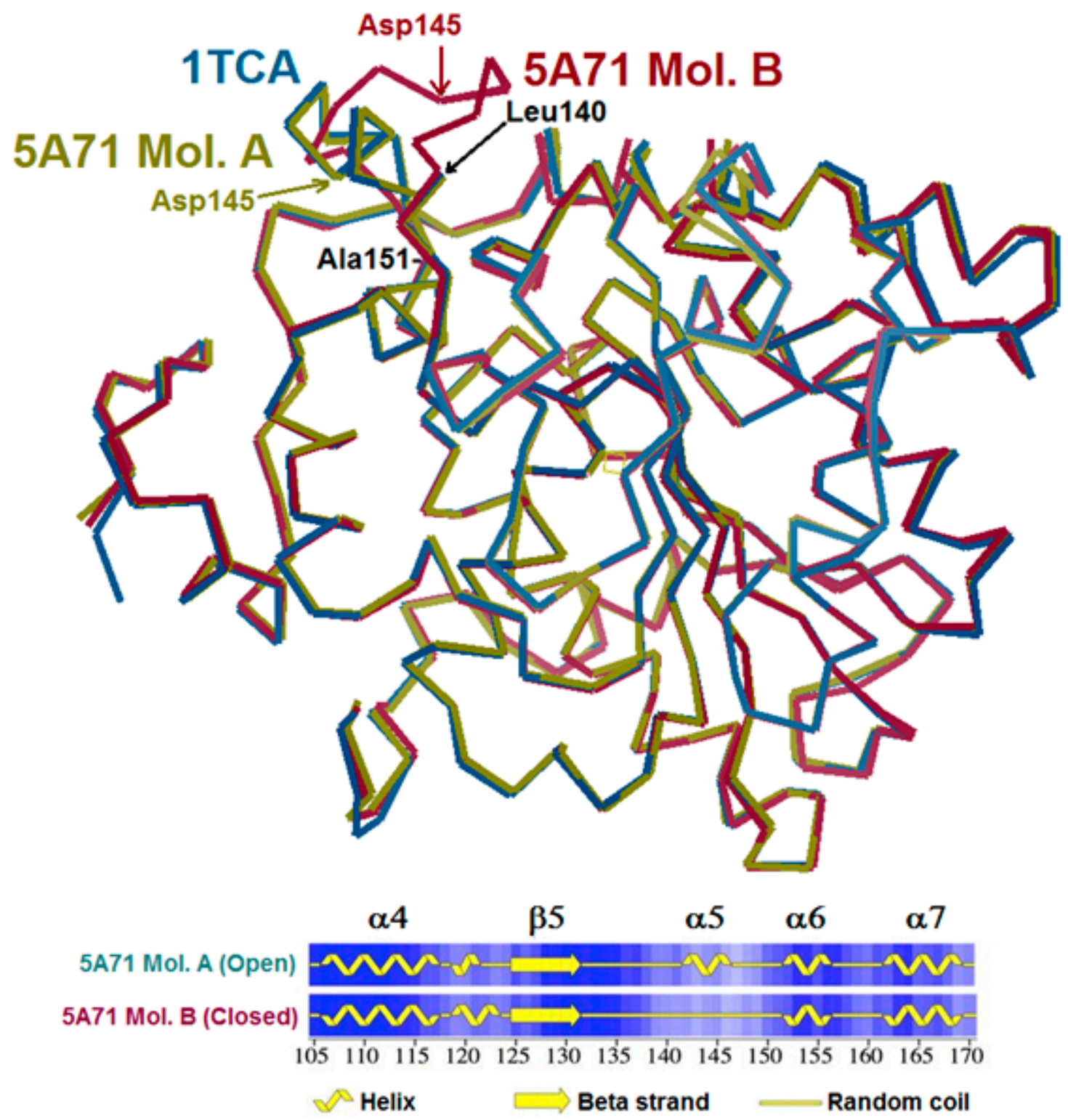

Figure 4. Superposition of the CAL-B structure 1TCA [27] and two monomers A and B of the CAL-B structure 5A71 [30]. In 5A71 monomer A (green), an $\alpha$-helix 5, which involves residues Leu140-Leu147, has a similar 'classical' open conformation, like in the 1TCA (blue) structure. The 5A71-A molecule superimposes with 1TCA with an RMSD value of 0.58 . The residue range $140-151$, in monomer B of 5A71 (red) undergoes dramatic conformational change and becomes an unfolded loop. The RMSD value of superimposed monomers A and B of 5A71 is equal to 1.41 [30]. The Figure was created using Coot software [39].

Probing the crystals using xenon (PDB entry 5A6V) validated again the presence of opened and closed conformations within the same asymmetric unit. Structure 5A71, which the authors consider as "native", is a CAL-B complex with sodium and potassium ions. Structure 5A6V, the author's "derivative", is a complex form with xenon, and was determined at a low resolution [30]. Determination of the open/closed stages of the CAL-B molecule at atomic resolution, made it possible to elucidate the role of residues Asp145 and Lys290 in the conformation change. The Asp145 residue is the only one amino acid in residue range 140-147 with a charged side chain. The side chain of Asp145, in monomer B moves by $7.4 \AA$, and generates a salt bridge with Lys290 from $\alpha$-helix 10. The distance between Lys290 NZ atom and Asp145 O 11 atom is $2.7 \AA$ (see Figure 4B,C in [30]). Residue Pro143 in monomer 
B (closed form) would clash with leucine-199 from a symmetrical molecule A (opened form) in the same unit cell [30].

The two structures: 5A6V and 5A71, which showed opened and closed states of CAL-B, could be directly related to the enzyme promiscuity [30]. These promiscuous conformations were later used as respective starting models, in a simulation related to lipase or esterase activity [38]. The opened (lipase) and closed (esterase) conformations were recognized by the motion of two helices $\alpha 5$ and $\alpha 10$ (see Figure 2 in [33]). The open conformation of CAL-B was shown to be induced by the self-assembly of the triglyceride moiety [38].

A comparison with the CAL-B structures mentioned above revealed the reasons for a lack of evidence for the closed conformation of a lid moiety. In the representative structure 1TCA [27], the residues Pro143-Asp145 from the lid segment make clash with residue Leu199 from symmetrical molecule. Instead, the lid moiety adopts an open $\alpha$-helical conformation, which is more compact. In structure 5A71, the monomers move with respect to each other to create closed conformation. Therefore, such clash is not formed. A similar clash between residues Pro143-Asp145 in molecule A and Leu199 in molecule B would happen in structure 1LBS [29]. In the same study [29], the authors determined the structure of other complex (1LBT), formed with methylphenta(oxyethyl)heptadecanoate (T80) at pH 4.0 (see Figure 3). This structure is packed very loosely in the unit cell and has a solvent content more than $60 \%$. The active site in $1 \mathrm{LBT}$ is solvent-exposed and there is no closed conformation. In the structure 5A71, the lid moiety is not exposed to the solvent because of tighter molecular packing in the crystal. In this case, the solvent content is low (38\%) [30].

Chimeras of CAL-B, which were engineered by swapping of lid moieties, illustrated large differences in kinetic parameters and in enantiomeric ratios for $p$-nitrophenyl ester hydrolysis [40]. The absence of Asp145 residue from helix $\alpha 5$ in two CAL-B variants, where the sequence of a lid fragment was cloned from Neurospora crassa and from Gibberella zeae, removed the dependence on $\mathrm{pH}$ in enzyme activity [40].

Using CAL-B as a model, the four enzyme variants have been engineered (PDB structures 6J1P, 6J1Q, 6J1R, 6J1S, 6J1T) [41,42]. These variants allowed to create all four stereoisomers in reactions of transestrification between racemic acids or alcohols in organic solvents. All mutants contained two monomers in asymmetric units. The secondary structure elements in both monomers were the same, except for the loop region 140-147, which displayed open and closed states for monomers A and B, respectively. As a difference from structure 5A71 [30], the closed conformation followed that arrangement from the structure 1TCA [27]. In the open conformation, the mobile loop 140-147 pointed away from the entrance to the reaction region, and therefore exposed the active site [41].

By using CAL-B as a model, a mutated Cys-His-Asp catalytic triad, and other mutations including W104V, V149G, A281Y, and A282Y, have been engineered [43]. These mutants showed a catalytic activity 40 times higher than the wild-type CAL-B in a hydrolysis reaction of 4-nitrophenyl benzoate, and tolerated large substrates [43]. Kinetic reactions with purified variant Ser105Cys showed that such a mutation lowered the catalytic productivity twice. Structural mutagenesis, crystal structures, kinetic studies, and theoretical calculations revealed dynamic features and explained that, instead of a coordinated process, a two-step mechanism including the Cys105-/His224+ zwitterion is preferred [43].

The Leu278 residue is known to be one of the catalytically important residues of CAL-B [44]. Structural mutagenesis of CAL-B enzyme allowed to design the transition state analogue, in which the catalytic serine-105 was modified by the phosphonate substituent [45]. In the inhibitor-bound structure 5GV5 [45], the side chain of Leu278 rotated away (with respect to structure 1TCA) to accommodate, as a substrate, the large sec-alcohol molecule. This structure demonstrated that serine-105 attacks the carbonyl part of a substrate and generates the tetrahedral intermediate. The departure of alcohol from the intermediate resulted in acylation of the enzyme. The further reaction with alcohol resulted in creation of second tetrahedral intermediate. Then, the oxyanion became hydrogen-bonded to the oxyanion hole, made by the presence of threonine-40 and glutamine-106 [45]. Therefore, as most lipases, 
CAL-B was found to be $R$-stereoselective for optically active sec-alcohols following the "Kazlauskas rule" [46].

Author Contributions: Conceptualization, J.B.; methodology, J.B.; software, J.B.; validation, J.B. and P.K.; formal analysis, P.K.; investigation, J.B.; resources, J.B.; data curation, J.B.; writing-original draft preparation, J.B.; writing - review and editing, J.B. and P.K.; visualization, J.B.; supervision, P.K.; project administration, J.B.; funding acquisition, P.K. All authors have read and agreed to the published version of the manuscript.

Funding: Financial support by the National Research Centre (NCN), Poland, grants: OPUS 2012/05/B/ST4/00075 for J.B., and OPUS 2016/23/B/ST5/02443 for P.K., is gratefully acknowledged.

Conflicts of Interest: The authors declare no conflict of interest.

\section{References}

1. Kirk, O.; Christensen, M.W. Lipases from Candida antarctica: Unique biocatalysts from a unique origin. Org. Prog. Res. Dev. 2002, 6, 446-451. [CrossRef]

2. Wu, Q.; Soni, P.; Reetz, M.T. Laboratory evolution of enantiocomplementary Candida antarctica lipase B mutants with broad substrate scope. J. Am. Chem. Soc. 2013, 135, 1872-1881. [CrossRef] [PubMed]

3. Sarmah, N.; Revathi, D.; Sheelu, G.; Rani, K.Y.; Sridhar, S.; Mehtab, V.; Sumana, C. Recent advances on sources and industrial applications of lipases. Biotechnol. Prog. 2018, 34, 5-28. [CrossRef] [PubMed]

4. Bornscheuer, U.T.; Kazlauskas, R.J. Hydrolases in Organic Synthesis: Regio- and Stereoselective Biotransformations; Wiley: Weinheim, Germany, 1999. [CrossRef]

5. Casas-Godoy, L.; Gasteazoro, F.; Duquesne, S.; Bordes, F.; Marty, A.; Sandoval, G. Lipases: An overview. Methods Mol. Biol. 2018, 1835, 3-38. [CrossRef] [PubMed]

6. Kiełbasiński, P.; Kwiatkowska, M.; Mikołajczyk, M. Chapter 10—Chiral heteroatom-containing compounds. In Future Directions in Biocatalysis, 2nd ed.; Elsevier: Amsterdam, The Netherlands, 2017; pp. 191-250. [CrossRef]

7. Alatorre-Santamaria, S.; Gotor-Fernandez, V.; Gotor, V. Chemoenzymatic synthesis of optically active cisand trans-2-(1H-imidazol-1-yl)cycloalkanamines. Eur. J. Org. Chem. 2011, 6, 1057-1063. [CrossRef]

8. Frykman, H.; Ohrner, N.; Norin, T.; Hult, K. S-Ethyl thiooctanoate as acyl donor in lipase-catalyzed resolution of secondary alcohols. Tetrahedron Lett. 1993, 34, 1367-1370. [CrossRef]

9. Patterson, L.D.; Miller, M.J. Enzymatic deprotection of the cephalosporin $3^{\prime}$-acetoxy group using Candida antarctica lipase B. J. Org. Chem. 2010, 75, 1289-1292. [CrossRef]

10. Santaniello, E.; Casati, S.; Ciuffreda, P. Lipase-catalyzed deacylation by alcoholysis: A selective, useful transesterification reaction. Curr. Org. Chem. 2006, 10, 1095-1123. [CrossRef]

11. Andualema, B.; Gessesse, A. Microbial lipases and their industrial applications: Review. Biotechnology 2012, 11, 100-118. [CrossRef]

12. Naik, S.; Basu, A.; Saikia, R.; Madan, B.; Paul, P.; Chaterjee, R.; Brask, J.; Svendsen, A. Lipases for use in industrial biocatalysis: Specificity of selected structural groups of lipases. J. Mol. Catal. B Enzym. 2010, 65, 18-23. [CrossRef]

13. Sharma, D.; Sharma, B.; Shukla, A.K. Biotechnological approach of microbial lipase: A review. Biotechnology 2011, 10, 3-40. [CrossRef]

14. Carboni-Oerlemans, C.; Dominguez de Maria, P.; Tuin, B.; Bargeman, G.; van der Meer, A.; van Gemert, R. Hydrolase-catalysed synthesis of peroxycarboxylic acids: Biocatalytic promiscuity for practical applications. J. Biotechnol. 2006, 126, 140-151. [CrossRef] [PubMed]

15. Carlqvist, P.; Svedendahl, M.; Branneby, C.; Hult, K.; Brinck, T.; Berglund, P. Exploring the active-site of a rationally redesigned lipase for catalysis of Michael-type additions. ChemBioChem 2005, 6, 331-336. [CrossRef] [PubMed]

16. Hult, K.; Berglund, P. Enzyme promiscuity: Mechanism and applications. Trends Biotechnol. 2007, 25, 231-238. [CrossRef] [PubMed]

17. Madalińska, L.; Kwiatkowska, M.; Cierpiał, T.; Kiełbasiński, P. Investigations on enzyme catalytic promiscuity: The first attempts at a hydrolytic enzyme-promoted conjugate addition of nucleophiles to $\alpha, \beta$-unsaturated sulfinyl acceptors. J. Mol. Catal. B. Enzym 2012, 81, 25-30. [CrossRef] 
18. Sharma, U.K.; Sharma, N.; Kumar, R.; Kumar, R.; Sinha, A.K. Biocatalytic promiscuity of lipase in chemoselective oxidation of aryl alcohols/acetates: A anique synergism of CAL-B and Br for the metal-free H2O2 activation. Org. Lett. 2009, 11, 4846-4848. [CrossRef]

19. Wu, Q.; Liu, B.-K.; Lin, X.-F. Enzymatic promiscuity for organic synthesis and cascade process. Curr. Org. Chem. 2010, 14, 1966-1988. [CrossRef]

20. Kundys, A.; Białecka-Florjańczyk, E.; Fabiszewska, A.; Małajowicz, J. Candida antarctica lipase B as catalyst for cyclic esters synthesis, their polymerization and degradation of aliphatic polyesters. J. Polym. Environ. 2018, 26, 396-407. [CrossRef]

21. Xie, Y.; An, J.; Yang, G.; Wu, G.; Zhang, Y.; Cui, L.; Feng, Y. Enhanced enzyme kinetic stability by increasing rigidity within the active site. J. Biol. Chem. 2014, 289, 7994-8006. [CrossRef]

22. Kim, S.-K.; Park, Y.-C.; Lee, H.-H.; Jeon, S.-T.; Min, W.-K.; Seo, J.-H. Simple amino acid tags improve both expression and secretion of Candida antarctica lipase B in recombinant Escherichia coli. Biotechnol. Bioeng. 2015, 112, 346-355. [CrossRef]

23. Qian, Z.; Horton, J.R.; Cheng, X.; Lutz, S. Structural redesign of lipase B from Candida antarctica by circular permutation and incremental truncation. J. Mol. Biol. 2009, 393, 191-201. [CrossRef] [PubMed]

24. Kiełbasiński, P.; Mikołajczyk, M. Chiral heteroatom-containing compounds. In Future Directions in Biocatalysis; Matsuda, T., Ed.; Elsevier: Amsterdam, The Netherlands, 2007; pp. 159-203. [CrossRef]

25. Krasiński, G.; Cypryk, M.; Kwiatkowska, M.; Mikołajczyk, M.; Kiełbasiński, P. Molecular modeling of the lipase-catalyzed hydrolysis of acetoxymethyl(i-propoxy) phenylphosphine oxide and its $P$-borane analogue. J. Mol. Graph. Model. 2012, 38, 290-297. [CrossRef] [PubMed]

26. Kwiatkowska, M.; Krasiński, G.; Cypryk, M.; Cierpiał, T.; Kiełbasiński, P. Lipase-mediated stereoselective transformations of chiral organophosphorus $P$-boranes revisited: Revision of the absolute configuration of alkoxy(hydroxymethyl)phenylphosphine P-boranes. Tetrahedron Asymmetry 2011, 22, 1581-1590. [CrossRef]

27. Uppenberg, J.; Hansen, M.T.; Patkar, S.; Jones, T.A. The sequence, crystal structure determination and refinement of two crystal forms of lipase B from Candida antarctica. Structure 1994, 2, 293-308. [CrossRef]

28. Strzelczyk, P.; Bujacz, G.D.; PKiełbasiński, P.; Błaszczyk, J. Crystal and molecular structure of hexagonal form of lipase B from Candida antarctica. Acta Biochim. Pol. 2016, 63, 103-109. [CrossRef]

29. Uppenberg, J.; Oehrner, N.; Norin, M.; Hult, K.; Kleywegt, G.J.; Patkar, S.; Waagen, V.; Anthonsen, T.; Jones, T.A. Crystallographic and molecular-modeling studies of lipase B from Candida antarctica reveal a stereospecificity pocket for secondary alcohols. Biochemistry 1995, 34, 16838-16851. [CrossRef]

30. Stauch, B.; Fisher, S.J.; Cianci, M. Open and closed states of Candida antarctica lipase B: Protonation and the mechanism of interfacial activation. J. Lipid Res. 2015, 56, 2348-2358. [CrossRef]

31. Cygler, M.; Schrag, J.D.; Ergan, F. Advances in structural understanding of lipases. Biotechnol. Genet. Eng. Rev. 1992, 10, 143-184. [CrossRef]

32. Palekar, A.A.; Vasudevan, P.T.; Yan, S. Purification of lipase: A review. Biocatal. Biotransform. 2009, 18, 177-200. [CrossRef]

33. Brämer, C.; Schreiber, S.; Scheper, T.; Beutel, S. Continuous purification of Candida antarctica lipase B using 3-membrane adsorber periodic counter-current chromatography. Eng. Life Sci. 2018, 18, 414-424. [CrossRef]

34. Van Tassel, L.; Moilanen, A.; Ruddock, L.W. Efficient production of wild-type lipase B from Candida antarctica in the cytoplasm of Escherichia coli. Protein Expr. Purif. 2020, 165, 105498. [CrossRef] [PubMed]

35. Potrzebowski, M.J.; Grossmann, G.; Błaszczyk, J.; Wieczorek, M.W.; Sieler, J.; Knopik, P.; Komber, H. X-ray and solid state NMR studies of bis(5,5-dimethyl-2-thioxo-1,3,2-dioxaphosphorinan-2-yl) disulfide and diselenide. Inorg. Chem. 1994, 33, 4688-4695. [CrossRef]

36. Berman, H.M.; Westbrook, J.; Feng, Z.; Gilliland, G.; Bhat, T.N.; Weissig, H.; Shindyalov, I.N.; Bourne, P.E. The Protein Data Bank. Nucleic Acids Res. 2000, 28, 235-242. [CrossRef] [PubMed]

37. Sehnal, D.; Rose, A.S.; Kovca, J.; Burley, S.K.; Velankar, S. Mol*: Towards a common library and tools for web molecular graphics. MolVA/EuroVis Proceedings, 2018. MolVA/EuroVis Proc. 2018. [CrossRef]

38. Benson, S.P.; Pleiss, J. Self-assembly nanostructures of triglyceride-water interfaces determine functional conformations of Candida antarctica lipase B. Langmuir 2017, 33, 3151-3159. [CrossRef]

39. Emsley, P.; Cowtan, K. Coot: Model-building tools for molecular graphics. Acta Cryst. 2004, D60, $2126-2132$. [CrossRef] 
40. Skjot, M.; De Maria, L.; Chatterjee, R.; Svendsen, A.; Patkar, S.A.; Ostergaard, P.R.; Brask, J. Understanding the plasticity of the $\alpha / \beta$ hydrolase fold: Lid swapping on the Candida antarctica lipase B results in chimeras with interesting biocatalytic properties. ChemBioChem 2009, 10, 520-527. [CrossRef]

41. Xu, J.; Cen, Y.; Singh, W.; Fan, J.; Wu, L.; Lin, X.; Zhou, J.; Huang, M.; Reetz, M.T.; Wu, Q. Stereodivergent protein engineering of a lipase to access all possible stereoisomers of chiral esters with two stereocenters. J. Am. Chem. Soc. 2019, 141, 7934-7945. [CrossRef]

42. Chen, H.; Meng, X.; Xu, X.; Liu, W.; Li, S. The molecular basis for lipase stereoselectivity. Appl. Microbiol. Biotechnol. 2018, 102, 3487-3495. [CrossRef]

43. Cen, Y.; Singh, W.; Arkin, M.; Moody, T.S.; Huang, M.; Zhou, J.; Wu, Q.; Reetz, M.T. Artificial cysteine-lipases with high activity and altered catalytic mechanism created by laboratory evolution. Nat. Commun. 2019, 10, 1-10. [CrossRef]

44. Park, C.-G.; Kwon, M.-A.; Song, J.-K.; Kim, D.-M. Cell-free synthesis and multifold screening of Candida antarctica lipase B (CalB) variants after combinatorial mutagenesis of hot spots. Biotechnol. Prog. 2011, 27, 47-53. [CrossRef] [PubMed]

45. Park, A.; Kim, S.; Park, J.; Joe, S.; Min, B.; Oh, J.; Song, J.; Park, S.-Y.; Park, S.; Lee, H. Structural and experimental evidence for the enantiomeric recognition toward a bulky sec-alcohol by Candida antarctica lipase B. ACS Catal. 2016, 6, 7458-7465. [CrossRef]

46. Kazlauskas, R.J.; Weissfloch, A.N.; Rappaport, A.T.; Cuccia, L.A. A rule to predict which enantiomer of a secondary alcohol reacts faster in reactions catalyzed by cholesterol esterase, lipase from Pseudomonas cepacia, and lipase from Candida rugosa. J. Org. Chem. 1991, 56, 2656-2665. [CrossRef]

(C) 2020 by the authors. Licensee MDPI, Basel, Switzerland. This article is an open access article distributed under the terms and conditions of the Creative Commons Attribution (CC BY) license (http://creativecommons.org/licenses/by/4.0/). 